\title{
Extracorporeal shock wave therapy with low-energy flux density inhibits hypertrophic scar formation in an animal model
}

\author{
JING-CHUN ZHAO, BO-RU ZHANG, LEI HONG, KAI SHI, WEI-WEI WU and JIA-AO YU \\ Burns and Plastic Reconstruction Unit, The First Hospital of Jilin University, Changchun, Jilin 130021, P.R. China
}

Received August 24, 2016; Accepted January 23, 2018

DOI: $10.3892 / \mathrm{ijmm} .2018 .3434$

\begin{abstract}
Hypertrophic scar is characterized by excessive deposits of collagen during skin wound healing, which could become a challenge to clinicians. This study assessed the effects of the extracorporeal shock wave therapy (ESWT) on hypertrophic scar formation and the underlying gene regulation. A rabbit ear hypertrophic scar model was generated and randomly divided into three groups: L-ESWT group to receive L-ESWT (energy flux density of $0.1 \mathrm{~mJ} / \mathrm{mm}^{2}$ ), H-ESWT (energy flux density of $0.2 \mathrm{~mJ} / \mathrm{mm}^{2}$ ) and sham ESWT group (S-ESWT). Hypertrophic scar tissues were then collected and stained with hematoxylin and eosin (H\&E) and Masson's trichrome staining, respectively, to assess scar elevation index (SEI), fibroblast density and collagen fiber arrangement. Expression of cell proliferation marker proliferating cell nuclear antigen (PCNA) and $\alpha$-smooth muscle actin ( $\alpha$-SMA) were assessed using RT-PCR and immunohistochemistry in hypertrophic scar tissues. H\&E staining sections showed significant reduction of SEI and fibroblast density in both ESWT treatment groups compared to S-ESWT, but there was no dramatic difference between L-ESWT and H-ESWT groups. Masson's trichrome staining showed that collagen fibers were more slender and broader and oriented in parallel to skin surface after administration of ESWT compared to control tissues. At the gene level, PCNA-positive fibroblasts and $\alpha$-SMA-positive myofibroblasts were significantly decreased after L-ESWT or H-ESWT compared to the controls. Furthermore, there was no significant difference in expression of PCNA mRNA between L-ESWT or H-ESWT and S-ESWT, whereas expression of $\alpha$-SMA mRNA significantly decreased in L-ESWT compared to that of H-ESWT and S-ESWT $(\mathrm{P}=0.002$ and $\mathrm{P}=0.030$, respectively). In conclusion, L-ESWT could be effective on suppression of hypertrophic scar formation by inhibition of
\end{abstract}

Correspondence to: Dr Jia-Ao Yu, Burns and Plastic Reconstruction Unit, The First Hospital of Jilin University, 71 Xinmin Street, Changchun, Jilin 130021, P.R. China

E-mail: bu_dong007@163.com

Key words: extracorporeal shock wave therapy, hypertrophic scar, proliferating cell nuclear antigen, $\alpha$-smooth muscle actin scar elevation index and fibroblast density as well as $\alpha$-SMA expression in hypertrophic scar tissues of the rabbit model.

\section{Introduction}

Clinically, a normal wound healing after a cut, burn, or injury will repair and close the wound by producing just sufficient amounts of collagen and tissues and thereafter, excessive cells, like fibroblasts will be eliminated through apoptosis $(1,2)$. However, the wound healing process is truly complex and fragile; for example, interruption or failure of the normal wound healing will lead to the formation of non-healing chronic wounds, whereas abnormal wound healing could became hypertrophic scar (2). Hypertrophic scar is characterized by excessive deposits of collagen during skin wound healing and has an adverse influence on patients psychologically and physically (3). Hypertrophic scar also causes physical dysfunction and symptoms, such as pain or itch. To date, the exact pathogenesis or molecular mechanism of hypertrophic scar formation remains to be defined, although extensive research and studies were reported during the past decades (3). As known, excessive synthesis of the extracellular matrix and collagen deposition due to abnormal fibroblast proliferation and differentiation could be responsible for hypertrophic scar formation. Previous studies revealed that there were differences in number and phenotype (4) and lower ability to produce collagenase between fibroblasts obtained from hypertrophic scar tissues and normal skin (4). Moreover, histological assessment of hypertrophic scar tissues showed characteristics: i) a significant increase in fibroblasts; ii) thin and disorderly organized wavy collagen III bundles arranged parallel to the epidermis; and iii) abundant of myofibroblast nodules and acidic mucopolysaccharides $(5,6)$. Molecularly, fibroblasts from hypertrophic scar tissues were shown to overexpress fibronectin (7), although the defined molecular changes of these fibroblasts from hypertrophic scar tissues remain to be determined.

Successful treatment of a hypertrophic scar has both psychological and physical significance. To date, treatment of a hypertrophic scar remains a challenge to clinicians due to lack of effective treatment options. For example, current therapeutic options available to treat hypertrophic scars include intralesion injection of corticosteroids or 5-fluorouracil (5-FU), silicone sheeting or gel, and radiotherapy, cryotherapy, excisional surgery, pressure therapy, fractional $\mathrm{CO}_{2}$ laser, or pulsed dye laser and their effectiveness on control of a hypertrophic 
scar is still debatable $(8,9)$. Originally, extracorporeal shock wave therapy (ESWT) (10) was used as an adjunct medical procedure to treat urinary lithotripsy (11) and more recently, its application has been extended to treat musculoskeletal disorders, fracture non-union, and soft tissue wounds (12-14); however, the precise ESWT mechanism on tissues remains unclear, but may be correlated with translating acoustic energy into mechanical stimulation or physical energy, and then exerts favorable biological responses to promote repair of compromised tissue via complex molecular and cellular interactions and changes (15). The biological effects of ESWT induced on tissues include increase in blood supply of tissues, promotion of burn wounds, and diabetic foot ulcer healing, and improvement of skin graft uptake $(10,16)$. Mechanistically, ESWT could induce local inflammation reaction and promote angiogenesis by recruitment of mesenchymal stem cells and endothelial progenitor cells to the injured site, stimulate cellular proliferation and regeneration, and decrease bacterial burden of the wound (17). In addition, based on ESWT energy flux density (EFD) level, ESWT can be divided into two categories, high EFD ESWT and low EFD ESWT $(18,19)$. Thus, in this study, we performed ESWT with low- or high-energy flux density versus control to assess their effects on hypertrophic scar formation and gene expression in a rabbit model. We expected to provide insightful information and a support of its clinic application in control of hypertrophic scar formation.

\section{Materials and methods}

Ethical approval. The animal protocol of this study was reviewed and approved by the Institutional Animal Care and Use Committee (IACUC) of the Institutional Ethics Committee at The First Hospital of Jilin University (Jilin, China).

Animals, the rabbit ear hypertrophic scar model, and treatment. Twenty-five adult laboratory white rabbits with an initial body weight of $2.3 \pm 0.2 \mathrm{~kg}$ were obtained from the Laboratory Animal Center of Jilin University and used in this study. The rabbit ear hypertrophic scar model was established based on our previous unpublished study. Briefly, rabbits were anesthetized with intravenous injection of ketamine $(30 \mathrm{mg} / \mathrm{kg})$ and four full-skin thickness circular wounds ( $15 \mathrm{~mm}$ diameter) with cartilage exposure were then inflicted on the ventral surface of each ear with a scalpel and covered with erythromycin eye ointment. The wound healing occurred spontaneously for three weeks and the control mice formed hypertrophic scars three weeks after surgery confirmed by histological examination.

The rabbits were randomly assigned into three groups with 32 scars for each group on day 21 after surgery, i.e., L-ESWT (energy flux density of $0.1 \mathrm{~mJ} / \mathrm{mm}^{2}$ ), H-ESWT (energy flux density of $0.2 \mathrm{~mJ} / \mathrm{mm}^{2}$ ), and sham ESWT group (S-ESWT). We then treated the rabbits with a shock wave therapy on each hypertrophic scar of rabbit ear with 500 impulses at a frequency of $8 \mathrm{~Hz}$ once a week for 4 weeks using Swiss DolorClast ${ }^{\circledR}$ Classic (EMS Electro Medical Systems, Nyon, Switzerland), while S-ESWT group of rabbits received identical treatment without any shock wave impulses.

Tissue harvest and processing. On day 1, 4, 7, 10, 14, 21, 28, and 35 during or after ESWT treatment, tissue samples were harvested for histological analysis and gene expression. The animals were administered with intravenous injection of ketamine $(30 \mathrm{mg} / \mathrm{kg})$ and half of the scar tissues were excised and fixed in $10 \%$ buffered formalin and embedded into paraffin for histological analysis and immunohistochemistry and another half of tissue samples were snap-frozen and stored in liquid nitrogen for RNA isolation and RT-PCR.

Hematoxylin and eosin and Masson's trichrome staining. Paraffin blocks of resected tissues from these rabbits were cut into $4-\mu \mathrm{M}$ thickness of tissue sections and stained with hematoxylin and eosin staining kit (cat. no. C0105; Beyotime Institute of Biotechnology, Jiangsu, China) and Masson's trichrome staining (Masson's Trichrome Stain kit, cat. no. TR-1303; ZSGB-Bio Co., Ltd., Beijing, China), respectively, according to the manufacturer's instructions. The stained tissue sections were then reviewed and photographed under an Olympus BX51 microscope (Olympus, Tokyo, Japan) to evaluate the scar elevation index (SEI), fibroblasts density, and collagen fiber arrangement by two investigators blindly.

Assessment of the SEI and fibroblasts density. For each scar, three photographs were prepared and evaluated by an investigator in a blinded manner to assess SEI, an average value to represent the degree of scar hyperplasia. Specifically, we measured scar thickness versus normal tissues and the ratio of 1 indicated that there was no difference in hypertrophy during the wound healing between scar and normal skin, while SEI 2 denoted $100 \%$ increase in wound thickness (20).

To assess the fibroblasts density in rabbit tissues for ESWT effectiveness, we calculated the numbers of fibroblasts in hematoxylin and eosin (H\&E)-stained tissue sections. Specifically, ten representative fields of the most fibroblast density areas were photographed under magnification, x400 and individual fibroblasts were counted. Fibroblast density per square millimeter was then calculated. The data were summarized as mean \pm SD of all tissue sections from each treatment group.

RT-PCR . Hypertrophic scar tissues were homogenized and total RNA was isolated using TRIzol ${ }^{\circledR}$ reagent (Invitrogen Life Technologies, Carlsbad, CA, USA) according to the manufacturer's instructions. The resulted RNA samples were quantified by using Epoch ${ }^{\mathrm{TM}}$ Multi-Volume Microplate Spectrophotometer system (BioTek Instruments, Inc., Winooski, VT, USA) and reversely transcribed into cDNA using M-MLV Reverse Transcriptase (Promega, Madison, WI, USA) according to the manufacturer's instructions. After that, PCR was carried out in a $25 \mu \mathrm{l}$ reaction mixture containing $12.5 \mu \mathrm{l} \mathrm{GoTaq}{ }^{\circledR}$ Green Master Mix (Promega), $1 \mu \mathrm{l}$ of cDNA, $1 \mu \mathrm{l}$ of each primer, $9.5 \mu \mathrm{l}$ nuclease-free water with the following conditions, $94^{\circ} \mathrm{C}$ for $30 \mathrm{sec}$ and $28-30$ cycles of $58^{\circ} \mathrm{C}$ [proliferating cell nuclear antigen (PCNA)], $56^{\circ} \mathrm{C}$ [ $\alpha$-smooth muscle actin ( $\alpha$-SMA)], or $65^{\circ} \mathrm{C}(\mathrm{GAPDH})$ for $30 \mathrm{sec}, 72^{\circ} \mathrm{C}$ for $40 \mathrm{sec}$. PCR products were then separated in $1.5 \%$ agarose gel containing ethidium bromide and images were taken by using the Tanon $2500 \mathrm{gel}$ imaging system (Tanon Science and Technology Co., Ltd., Shanghai, China) for quantification with Tanon gel image system 1D software (version 4.1.2). Primers were designed and synthesized by BGI (Shenzhen, China) and primer sequences 

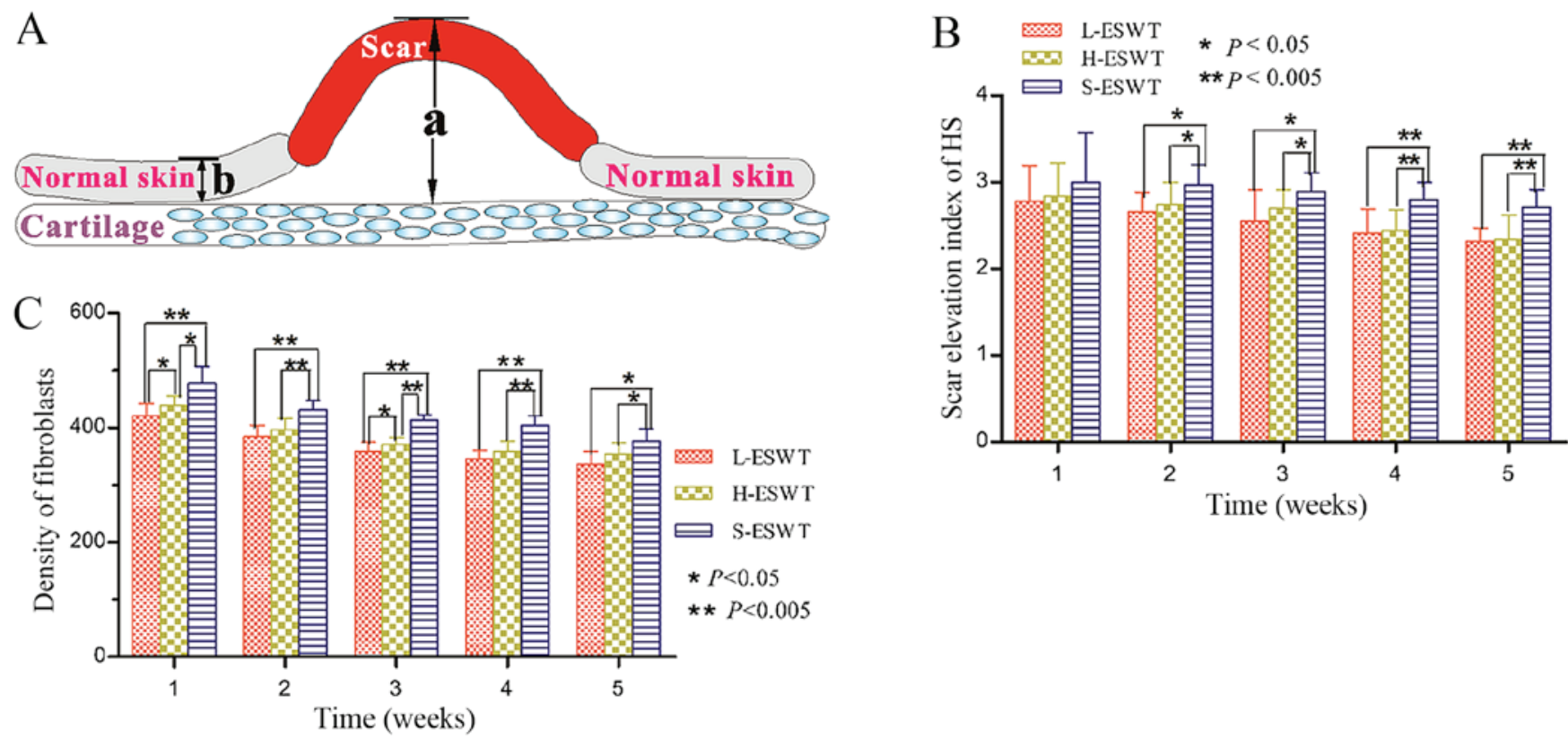

Time (weeks)

Figure 1. The rabbit ear model of hypertrophic scar and effects of extracorporeal shock wave therapy (ESWT). (A) The model of scar elevation index (SEI). a, The height from the peak of hypertrophic scar to the cartilage; $b$, the height from the surface of normal skin to the cartilage. SEI=a/b. (B) Effects of ESWT administration on SEI reduction in the rabbit model of hypertrophic scar. (C) Effects of ESWT administration on inhibition of fibroblasts density.

were: PCNA forward, 5'-GGTTCTTCCAACTCTGCCA CTA-3' and reverse, 5'-GGTTTTCTCTTTGCCTTCCCTA-3' to amplify a 215 base pair (bp) of PCR product; $\alpha$-SMA forward, 5'-TCGACATCAGGAAGGACCTCT-3' and reverse, 5'-CATCTGCTGAAAGGTGGACAG-3' to generate a 206 bp band; and GAPDH forward, 5'-GCGCCTGGTCACCAGGG CTGCTT-3' and reverse, 5'-TGCCGAAGTGGTCGTGGATG ACCT-3' to obtain a 464 bp product.

Immunohistochemistry. Immunohistochemistry was used to detect the expression of cell proliferation marker PCNA and smooth muscle marker $\alpha$-SMA in hypertrophic scar tissues. Specifically, tissue sections were deparaffinized in xylene and rehydrated in a series of graded ethanol and then subjected to the antigen retrieval by cooking in $0.01 \mathrm{M}$ citrate buffer (pH 6.0) for $3 \mathrm{~min}$. After washed with phosphate-buffered saline (PBS) briefly three times, the endogenous peroxidase activity in tissues was blocked by treating the tissue sections with $0.3 \% \mathrm{H}_{2} \mathrm{O}_{2}$ in $70 \%$ methanol at room temperature for $20 \mathrm{~min}$ and tissues sections were incubated in $10 \%$ normal goat serum at room temperature for $20 \mathrm{~min}$ and further incubated with a mouse anti-rabbit monoclonal PCNA antibody (cat. no. BM0104; Wuhan Boster Biological Technology, Ltd., Wuhan, China) or a mouse monoclonal anti-rabbit $\alpha$-SMA antibody (cat no. BM0002; Wuhan Boster Biological Technology, Ltd.) both at 1:100 dilution at $4^{\circ} \mathrm{C}$ overnight. The next day, the tissue sections were washed in PBS three times and then incubated with UltraSensitive ${ }^{\mathrm{TM}}$ SP (mouse) IHC kit (cat. no. KIT-9702; Fujian Maxin Biological, Fujian, China) at the room temperature for $2 \mathrm{~h}$ and then subsequently with a streptavidin-peroxidase solution at the room temperature for $2 \mathrm{~h}$. The color reaction was performed using the 3,3'-diaminobenzidine (DAB) detection kit (cat. no. KIT-0017; Fujian Maxin Biological) according to the manufacturer's instructions and the tissue sections were briefly counterstained with hematoxylin. The immunostained tissue sections were then reviewed and photographed under an Olympus BX51 microscope (Olympus, Tokyo, Japan) by two investigators in a blinded manner. Six representative areas of the most PCNA or $\alpha$-SMApositive cells were photographed at $\mathrm{x} 400$ magnification and counted for PCNA or $\alpha$-SMA-positive cells. The results were expressed as mean \pm SD of PCNA or $\alpha$-SMA-positive cells/ total number of cells x $100 \%$.

Statistical analysis. All data were expressed as mean \pm standard deviation (SD) and were analyzed using SPSS statistical software, version 19.0 (SPSS, Inc., Chicago, IL, USA). Histology data were compared and analyzed using the paired t-test and gene expression data were analyzed using one-way analysis of variance (ANOVA). A P-value $\leq 0.05$ was considered statistically significant.

\section{Results}

ESWT reduction of the SEI and fibroblast density in the rabbit ear hypertrophic scar model. In this study, we first established the rabbit ear hypertrophic scar model and then treated them with ESWT and found that only from day 14, there was a significant difference in SEI between L-ESWT or H-ESWT group and S-ESWT group $(2.66 \pm 0.22$ or $2.74 \pm 0.26$ vs. $2.97 \pm 0.23$; $\mathrm{P}=0.010$ and $\mathrm{P}=0.026$ between L-ESWT or H-ESWT and S-ESWT, respectively). However, there was noticeable difference between L-ESWT and H-ESWT (Fig. 1 and Table I). We also found that consecutive ESWT for 35 days significantly inhibited scar hyperplasia in L-ESWT and H-ESWT groups $(\mathrm{P}<0.05)$, while there was no significant difference between L-ESWT and H-ESWT (Fig. 1 and Table I).

Furthermore, one week after ESWT, there was a significant difference in fibroblast density occurring between L-ESWT or H-ESWT group and S-ESWT group $\left(420.26 \pm 21.44 / \mathrm{mm}^{2}\right.$, 
Table I. Effect of ESWT administration on suppression of SEI in the rabbit model of hypertrophic scar formation (mean \pm SD).

\begin{tabular}{lcccc}
\hline Therapy & 1 week & 2 weeks & 3 weeks & 4 weeks \\
\hline L-ESWT & $2.78 \pm 0.41$ & $2.66 \pm 0.22^{\mathrm{a}}$ & $2.55 \pm 0.36^{\mathrm{a}}$ & $2.41 \pm 0.28^{\mathrm{a}}$ \\
H-ESWT & $2.84 \pm 0.38$ & $2.74 \pm 0.26^{\mathrm{a}}$ & $2.70 \pm 0.20^{\mathrm{a}}$ & $2.44 \pm 0.24^{\mathrm{a}}$ \\
S-ESWT & $3.00 \pm 0.57$ & $2.97 \pm 0.23$ & $2.89 \pm 0.22$ & $2.80 \pm 0.20$ \\
\hline
\end{tabular}

SEI, scar elevation index; L-ESWT, low-energy extracorporeal shock wave therapy; H-ESWT, high-energy extracorporeal shock wave therapy; S-ESWT, sham group without extracorporeal shock wave therapy. ${ }^{\mathrm{a}} \mathrm{P}<0.05$ compared to S-ESWT group.

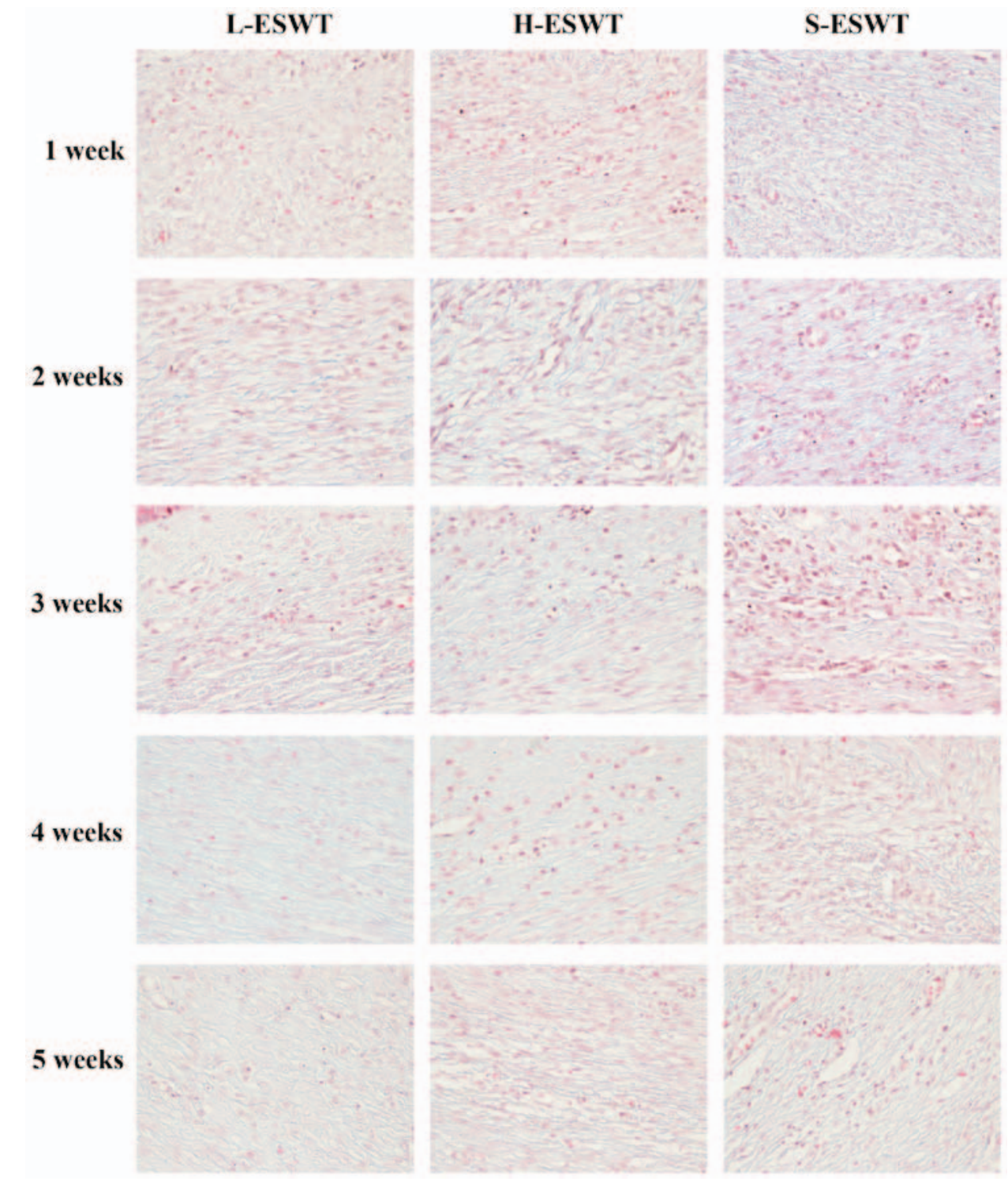

Figure 2. Effects of extracorporeal shock wave therapy (ESWT) administration on modulation of collagen arrangement in hypertrophic scar tissues. The animals were subjected to L-ESWT or H-ESWT for up to 5 weeks and the hypertrophic scar tissues were processed for Masson's trichrome staining and evaluation of collagen arrangement. Magnification, x200.

or $439.53 \pm 16.37 / \mathrm{mm}^{2}$ vs. $477.80 \pm 29.56 / \mathrm{mm}^{2} ; \mathrm{P}=0.003$ or $\mathrm{P}=0.009$ between L-ESWT or H-ESWT and S-ESWT, respectively). Moreover, there was also statistical significance in fibrobast density between L-ESWT and H-ESWT groups $(\mathrm{P}=0.015)$. Consecutive administration of ESWT for 35 days significantly reduced the number of fibroblasts between both ESWT and S-ESWT groups; however, there was no significant difference between L-ESWT and H-ESWT found in the longer treatment (Fig. 1).

ESWT improvement of collagen arrangement in the rabbit ear hypertrophic scar model. Masson's trichrome staining showed that number of the collagen bundles was reduced and the collagen bundles were much thinner and looser and 
Table II. Effect of ESWT administration on suppression of PCNA-positive cells in the rabbit model of hypertrophic scar formation $($ mean $\pm \mathrm{SD})$.

\begin{tabular}{|c|c|c|c|c|c|}
\hline Therapy & 1 week & 2 weeks & 3 weeks & 4 weeks & 5 weeks \\
\hline L-ESWT & $21.74 \pm 3.68^{b}$ & $32.61 \pm 4.26^{\mathrm{b}}$ & $42.49 \pm 4.18^{b}$ & $32.01 \pm 3.10^{\mathrm{b}}$ & $25.44 \pm 2.33^{b}$ \\
\hline H-ESWT & $24.42 \pm 4.28$ & $36.04 \pm 4.88^{\mathrm{b}}$ & $46.81 \pm 5.31$ & $35.91 \pm 5.83^{\mathrm{b}}$ & $32.89 \pm 3.22^{b}$ \\
\hline S-ESWT & $27.47 \pm 4.41$ & $41.06 \pm 3.45$ & $50.62 \pm 5.62$ & $45.98 \pm 4.25$ & $49.89 \pm 2.67$ \\
\hline
\end{tabular}

PCNA, proliferating cell nuclear antigen; L-ESWT, low-energy extracorporeal shock wave therapy; H-ESWT, high-energy extracorporeal shock wave therapy; S-ESWT, sham group without extracorporeal shock wave therapy. ${ }^{a} \mathrm{P}<0.05$ compared to H-ESWT group; ${ }^{\text {b }}<0.05$ compared to S-ESWT group.
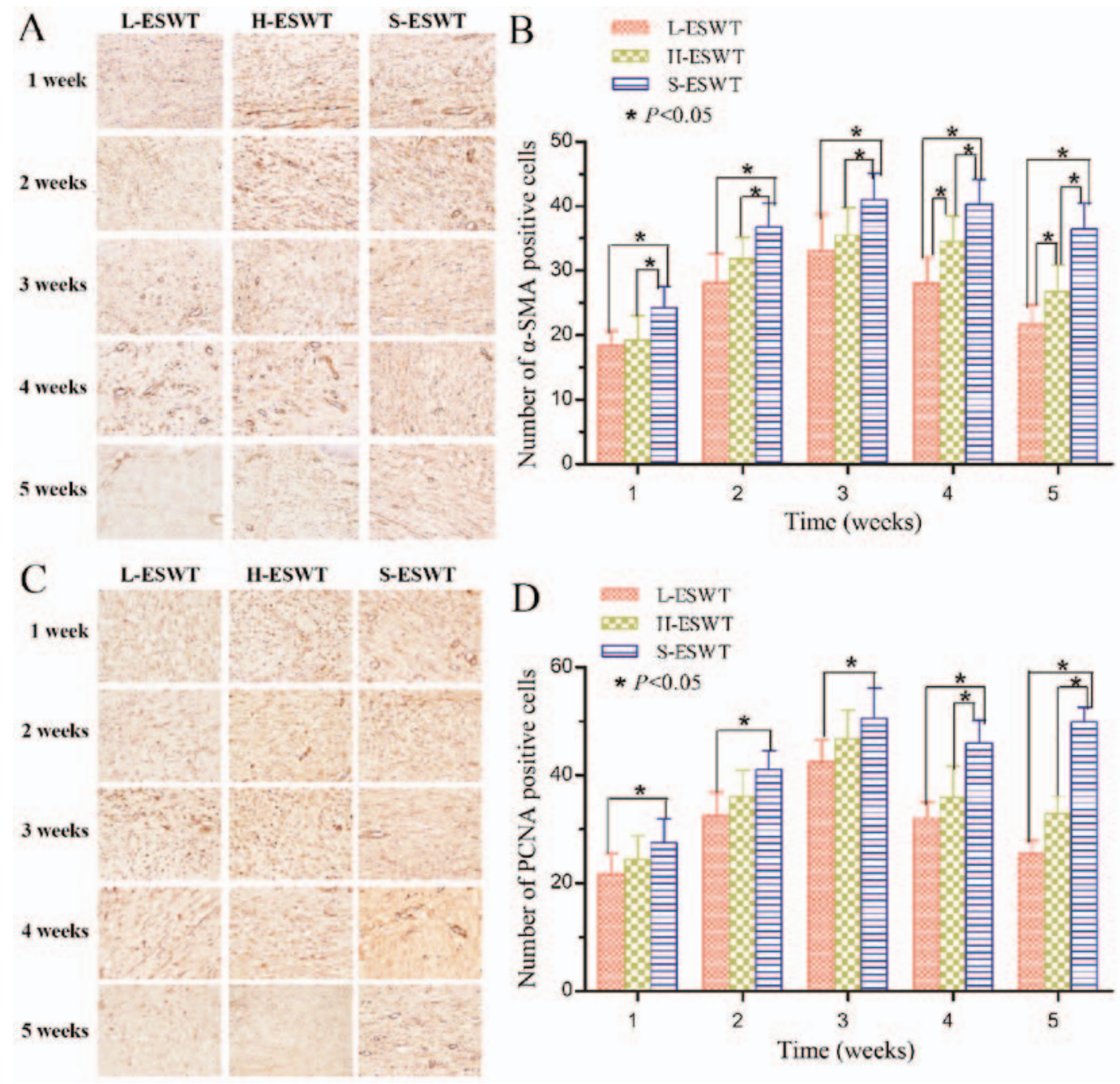

Figure 3. Effects of extracorporeal shock wave therapy (ESWT) administration on suppression of proliferating cell nuclear antigen (PCNA) and $\alpha$-smooth muscle actin ( $\alpha$-SMA) protein expression. The animals were subjected to L-ESWT or H-ESWT for up to 5 weeks and the hypertrophic scar tissues were processed for immunohistochemical analysis. (A and B) $\alpha$-SMA and (C and D) PCNA. Magnification, x200. The graphs are summarized data of the immunostaining.

regularly organized in L-ESWT and H-ESWT-treated hypertrophic scar tissues, whereas the collagen fibers were thicker, denser, more abundant and disorganized in S-ESWT (Fig. 2).

ESWT suppressionofPCNA and $\alpha$-SMA expression.PCNA and $\alpha$-SMA proteins were assessed using immunohistochemistry and the data showed that fibroblasts and endothelial cells of vessels expressed high levels of PCNA proteins, whereas L-ESWT or H-ESWT significantly reduced PCNA-positive cells compared to that of S-ESWT, and L-ESWT showed much earlier in reduction of PCNA expression than that of H-ESWT $(\mathrm{P}<0.05$ in 7 and 28 days between L-ESWT or H-ESWT and S-ESWT, respectively. However, there was no significant difference between L-ESWT and H-ESWT (Fig. 3 and Table II).

Moreover, levels of $\alpha$-SMA-positive myofibroblasts also showed a trend for first increase and late decrease after L-ESWT or H-ESWT and such a trend was much earlier 
Table III. Effect of ESWT administration on suppression of $\alpha$-SMA-positive cells in the rabbit model of hypertrophic scar formation (mean $\pm \mathrm{SD})$.

\begin{tabular}{lccccc}
\hline Therapy & 1 week & 2 weeks & 3 weeks & 4 weeks & 5 weeks \\
\hline L-ESWT & $18.44 \pm 2.26^{\mathrm{b}}$ & $28.21 \pm 4.52^{\mathrm{b}}$ & $33.09 \pm 5.65^{\mathrm{b}}$ & $28.02 \pm 4.01^{\mathrm{a}, \mathrm{b}}$ & $21.62 \pm 3.11^{\mathrm{a}, \mathrm{b}}$ \\
H-ESWT & $19.22 \pm 3.88^{\mathrm{b}}$ & $31.94 \pm 3.26^{\mathrm{b}}$ & $35.51 \pm 4.32^{\mathrm{b}}$ & $34.51 \pm 3.99^{\mathrm{b}}$ & $26.73 \pm 4.12^{\mathrm{b}}$ \\
S-ESWT & $24.27 \pm 3.26$ & $36.76 \pm 3.67$ & $41.02 \pm 4.09$ & $40.38 \pm 3.75$ & $36.48 \pm 4.01$ \\
\hline
\end{tabular}

L-ESWT, low-energy extracorporeal shock wave therapy; H-ESWT, high-energy extracorporeal shock wave therapy; S-ESWT, sham group without extracorporeal shock wave therapy. ${ }^{\text {a }}<0.05$ compared to H-ESWT group; ${ }^{b} \mathrm{P}<0.05$ compared to S-ESWT group. $\alpha$-SMA, $\alpha$-smooth muscle actin.
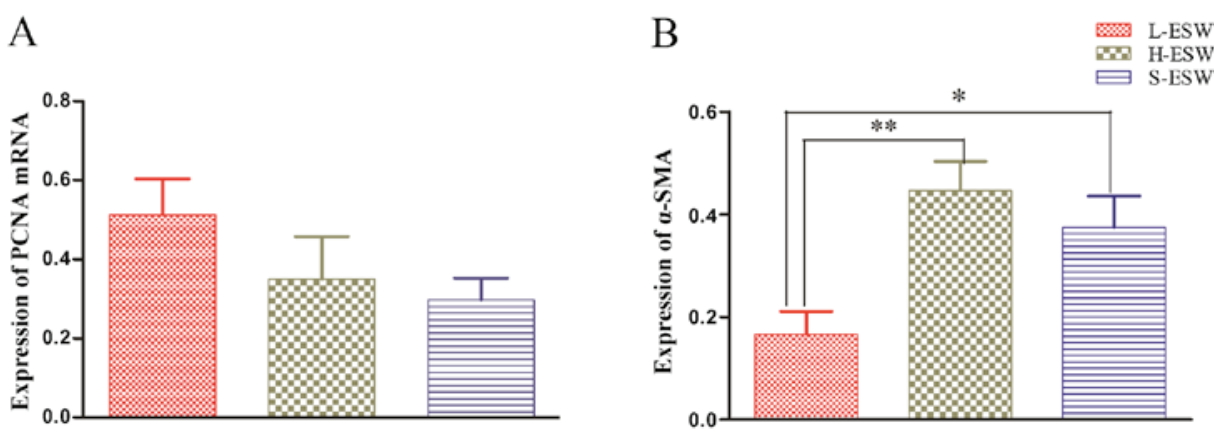

Figure 4. Effects of extracorporeal shock wave therapy (ESWT) administration on modulation of proliferating cell nuclear antigen (PCNA) and $\alpha$-smooth muscle actin ( $\alpha$-SMA) mRNA level. The animals were subjected to L-ESWT or H-ESWT for up to 5 weeks and the hypertrophic scar tissues were processed for RT-PCR analysis of (A) PCNA and (B) $\alpha$-SMA mRNA.

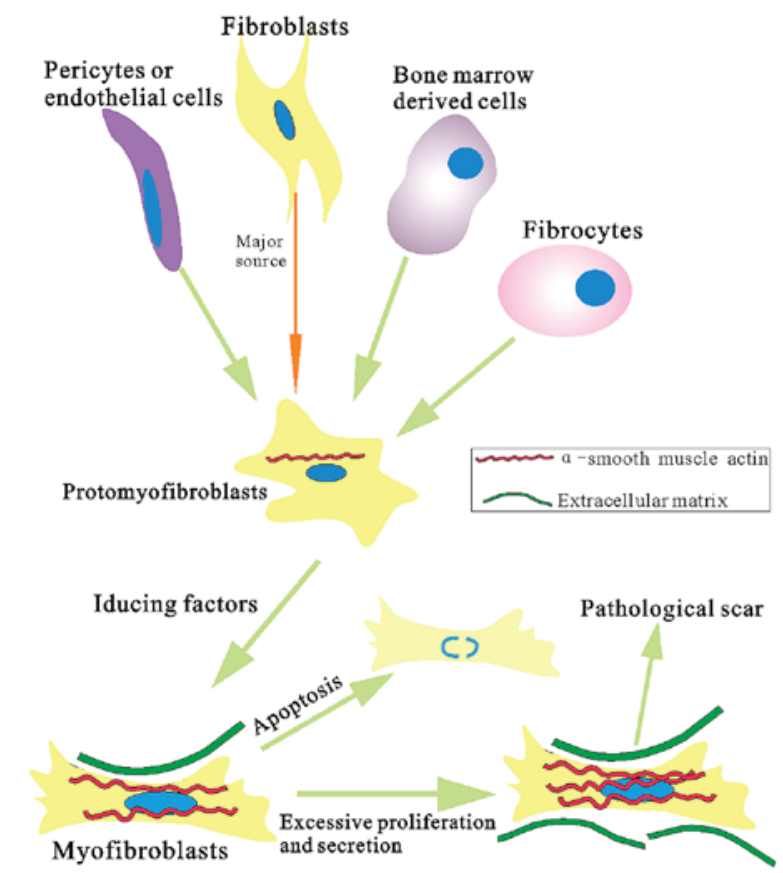

Figure 5. Schematic diagram of myofibroblast sources and differentiation. Inducing factors, e.g., transforming growth factor- $\beta$ (TGF- $\beta$ ), mechanical stress and integrin would induce fibroblasts change into protomyofibroblasts and then transition into differentiated myofibroblasts characterized by contractile properties because of the formation of robust stress fibers containing $\alpha$-smooth muscle actin ( $\alpha$-SMA).

in L-ESWT group. The number of $\alpha$-SMA-positive cells in L-ESWT or H-ESWT groups were much lower than that of
S-ESWT $(\mathrm{P}<0.05)$; however, there was no statistical significance found between L-ESWT and H-ESWT until four weeks later $(\mathrm{P}<0.05$; Fig. 3 and Table III).

L-ESWT downregulation of $\alpha$-SMA mRNA level. The effects of L-ESWT and H-ESWT on PCNA and $\alpha$-SMA mRNA expression was also assessed by using RT-PCR. The data showed that there was no significant difference in PCNA mRNA level among the three experimental groups, whereas level of $\alpha$-SMA mRNA was significantly lower in L-ESWT compared to that in H-ESWT and S-ESWT groups $(\mathrm{P}=0.002$ and $\mathrm{P}=0.039$, respectively), although there was no statistical significance observed between H-ESWT and S-ESWT (Fig. 4).

\section{Discussion}

Successful treatment of hypertrophic scar has both psychological and physical significance. Hypertrophic scar causes cosmetic and social stress on affected persons, especially girls in addition to the unwanted appearance and physical dysfunction or symptoms, such as pain or itch. However, to date, treatment of hypertrophic scar remains a challenge to clinicians due to lack of effective treatment options. Although various therapeutic modalities have been developed showing some efficacy on hypertrophic scar during the past decades, there is still a paucity of standard of care for hypertrophic scar patients. Better understanding of the underlying molecular mechanisms responsible for unwanted wound healing and hypertrophic scar formation could help us to design or identify novel therapeutic methods. Therefore, identification and assessment of more effective but less invasive 
therapeutic options could help such patients clinically. Thus, in this study, we performed ESWT with low- or high-energy flux density versus control to assess their effects on hypertrophic scar formation and gene expression. We found that both ESWT treatment groups significantly reduced the scar elevation index and fibroblast density compared to controls. ESWT treatment also showed that collagen fibers were more slender and broader and oriented in parallel to skin surface compared to control tissues. Molecularly, ESWT treatment suppressed proliferation of PCNA-positive fibroblasts and $\alpha$-SMA-positive myofibroblasts compared to the controls. Nevertheless, both L-ESWT and H-ESWT showed effective suppression of hypertrophic scar formation by inhibition of scar elevation index and fibroblast density as well as PCNA and $\alpha$-SMA expression in hypertrophic scar tissues. Simultaneously, we also evaluated the effects of ESWT on regulation of PCNA and $\alpha$-SMA mRNA and found that L-ESWT was able to significantly downregulate level of $\alpha$-SMA mRNA in the hypertrophic scar tissues, whereas it was unable to alter level of PCNA mRNA. Future clinical trials will confirm our current finding.

As a novel adjunct management option for soft tissue wound healing and musculoskeletal disorders, ESWT has received extensive attention due to its efficacious, safe, non-invasive, and cost-effective nature by utilizing abrupt and high amplitude pulses of mechanical energy, which is similar to sound wave, to treat human diseases (22-25). Previous studies showed that ESWT could stimulate angiogenesis and neurogenesis (26) and mechanistically, ESWT may induce cells to undergo microtrauma and therefore promotes inflammation and catabolic processes and wound healing (27). However, to date, there has been only a few of studies evaluated ESWT to manage hypertrophic scars. For example, Fioramonti et al (28) documented that ESWT could improve texture and color of post-burn scars in 16 patients. Saggini et al (29) observed significant early improvement of pain, mobility, and modified Vancouver Scar Scale (VSS) in retracting scars of the hands after treatment with unfocused shock wave treatment. Our current data further supported the usefulness of ESWT in management of hypertrophic scar and found that ESWT could histologically improve SEI, fibroblasts density, and collagen fiber arrangement in hypertrophic scar tissues.

Molecularly, abnormal proliferation and differentiation of fibroblasts play a key role in hypertrophic scar formation and remodeling (30). Thus, in the present study, we assessed PCNA expression, which is a DNA polymerase delta auxiliary protein that synthesized and expressed in proliferating cells to be essential for cell replication and cell cycle progression $(31,32)$. Furthermore, fibroblast differentiation into myofibroblasts is closely associated with $\alpha$-SMA expression during wound healing process and myofibroblasts have the ability to increase collagen synthesis and contractile activity, but decrease synthesis of collagenase, and become insensitive to apoptotic inductors $(33,34)$ (Fig. 5). Differentiation of myofibroblasts is thought to play a key role in fibrotic disease and involved in many fibrosis of organs (35). Our current data showed that ESWT was able to inhibit expression of $\alpha$-SMA mRNA and reduce the number of PCNA and $\alpha$-SMA-positive cells. Further confirming the usefulness of ESWT in management of hypertrophic scar. Regarding the discrepancy between expression of PCNA protein and mRNA in the present study, it is necessary to further investigate with carefully controls each time-point using qRT-PCR for confirmation. Nevertheless, expression of gene protein and mRNA may not always be parallel since they are regulated differently (21).

In conclusion, both low- and high-energy ESWT was able to suppress hypertrophic scar formation improving the scar elevation index and fibroblast density compared to controls in hypertrophic scar tissues of the rabbit model in an early stage. This may be associated with the effect of ESWT on inhibition of $\alpha$-SMA expression of hypertrophic scar tissues. Future studies are essential to investigate other potential mechanisms in order to further develop and improve efficacy of L-ESWT-based therapy of hypertrophic scar clinically.

\section{Acknowledgements}

Not applicable.

\section{Funding}

No funding was received.

\section{Availability of data and material}

The datasets used and/or analyzed during the current study are available from the corresponding author on reasonable request.

\section{Authors' contributions}

ZJC conceived and designed the study, and wrote the paper. ZBR, HL and SK conducted the experiment and collected the data. WWW analyzed the data. YJA made scientific revisions. All authors read and approved the final manuscript.

\section{Ethics approval and consent to participate}

Not applicable.

\section{Consent for publication}

Not applicable.

\section{Competing interests}

The authors declare that they have no competing interests.

\section{References}

1. Stadelmann WK, Digenis AG and Tobin GR: Physiology and healing dynamics of chronic cutaneous wounds. Am J Surg 176 (Suppl 2A): 26S-38S, 1998.

2. Midwood KS, Williams LV and Schwarzbauer JE: Tissue repair and the dynamics of the extracellular matrix. Int J Biochem Cell Biol 36: 1031-1037, 2004.

3. Gauglitz GG, Korting HC, Pavicic T, Ruzicka $\mathrm{T}$ and Jeschke MG: Hypertrophic scarring and keloids: pathomechanisms and current and emerging treatment strategies. Mol Med 17: 113-125, 2011.

4. Nedelec B, Shankowsky H, Scott PG, Ghahary A and Tredget EE: Myofibroblasts and apoptosis in human hypertrophic scars: the effect of interferon-alpha2b. Surgery 130: 798-808, 2001

5. Slemp AE and Kirschner RE: Keloids and scars: a review of keloids and scars, their pathogenesis, risk factors, and management. Curr Opin Pediatr 18: 396-402, 2006. 
6. Yang L, Scott PG, Dodd C, Medina A, Jiao H, Shankowsky HA, Ghahary A and Tredget EE: Identification of fibrocytes in postburn hypertrophic scar. Wound Repair Regen 13: 398-404, 2005

7. Ali SS, Hajrah NH, Ayuob NN, Moshref SS and Abuzinadah OA Morphological and morphometric study of cultured fibroblast from treated and untreated abnormal scar. Saudi Med J 31: 874-881, 2010.

8. Williams CC and De Groote S: Clinical inquiry: what treatment is best for hypertrophic scars and keloids? J Fam Pract 60 757-758, 2011.

9. Shridharani SM, Magarakis M, Manson PN, Singh NK, Basdag B and Rosson GD: The emerging role of antineoplastic agents in the treatment of keloids and hypertrophic scars: a review. Ann Plast Surg 64: 355-361, 2010.

10. Dymarek R, Halski T, Ptaszkowski K, Slupska L, Rosinczuk J and Taradaj J: Extracorporeal shock wave therapy as an adjunct wound treatment: a systematic review of the literature. Ostomy Wound Manage 60: 26-39, 2014.

11. Chaussy C, Brendel W and Schmiedt E: Extracorporeally induced destruction of kidney stones by shock waves. Lancet 2 : 1265-1268, 1980.

12. Rassweiler J, Rassweiler MC, Frede T and Alken P: Extracorporeal shock wave lithotripsy: an opinion on its future. Indian J Urol 30: 73-79, 2014.

13. Valchanou VD and Michailov P: High energy shock waves in the treatment of delayed and nonunion of fractures. Int Orthop 15: 181-184, 1991.

14. Maffulli G, Hemmings S and Maffulli N: Assessment of the effectiveness of extracorporeal shock wave therapy (ESWT) for soft tissue injuries (ASSERT): an online database protocol. Transl Med UniSa 10: 46-51, 2014.

15. Mittermayr R, Hartinger J, Antonic V, Meinl A, Pfeifer S, Stojadinovic A, Schaden W and Redl H: Extracorporeal shock wave therapy (ESWT) minimizes ischemic tissue necrosis irrespective of application time and promotes tissue revascularization by stimulating angiogenesis. Ann Surg 253: 1024-1032, 2011.

16. Zhao JC, Xian CJ and Yu JA: Advancement in the research of effect of extracorporeal shock wave therapy on wound angiogenesis. Chin J Inj Repair Wound Healing 9: 80-84, 2014.

17. Zhao J, Xue Y, Yu J, Shi K, Xian C and Zhou X: Advances in the research of mechanism of enhancement of wound healing with extracorporeal shock wave therapy. Zhonghua Shao Shang Za Zhi 31: 315-317, 2015 (In Chinese).

18. Speed C: A systematic review of shockwave therapies in soft tissue conditions: focusing on the evidence. Br J Sports Med 48: $1538-1542,2014$

19. Goertz O, Lauer H, Hirsch T, Ring A, Lehnhardt M, Langer S, Steinau HU and Hauser J: Extracorporeal shock waves improve angiogenesis after full thickness burn. Burns 38: 1010-1018, 2012

20. Kloeters O, Tandara A and Mustoe TA: Hypertrophic scar model in the rabbit ear: a reproducible model for studying scar tissue behavior with new observations on silicone gel sheeting for scar reduction. Wound Repair Regen 15 (Suppl 1): S40-S45, 2007.

21. Zhou M, Li LH, Peng H, Li R, Feng CC, Xu WD, Leng RX, Pan HF and Ye DQ: Decreased ITGAM and Fc $\gamma$ RIIIA mRNA expression levels in peripheral blood mononuclear cells from patients with systemic lupus erythematosus. Clin Exp Med 14: 269-274, 2014.
22. Wang CJ, Ko JY, Chan YS, Weng LH and Hsu SL: Extracorporeal shockwave for chronic patellar tendinopathy. Am J Sports Med 35: 972-978, 2007.

23. Yin MC, Ye J, Yao M, Cui XJ, Xia Y, Shen QX, Tong ZY, Wu XQ, Ma JM and Mo W: Is extracorporeal shock wave therapy clinical efficacy for relief of chronic, recalcitrant plantar fasciitis? A systematic review and meta-analysis of randomized placebo or active-treatment controlled trials. Arch Phys Med Rehabil 95: $1585-1593,2014$

24. Thiele S, Thiele R and Gerdesmeyer L: Lateral epicondylitis: this is still a main indication for extracorporeal shockwave therapy. Int J Surg 24 (Pt B): 165-170, 2015.

25. Wang CJ, Cheng JH, Kuo YR, Schaden W and Mittermayr R: Extracorporeal shockwave therapy in diabetic foot ulcers. Int J Surg 24 (Pt B): 207-209, 2015.

26. Wang CJ, Ko JY, Kuo YR and Yang YJ: Molecular changes in diabetic foot ulcers. Diabetes Res Clin Pract 94: 105-110, 2011.

27. Waugh CM, Morrissey D, Jones E, Riley GP, Langberg H and Screen HR: In vivo biological response to extracorporeal shockwave therapy in human tendinopathy. Eur Cell Mater 29: 268-280, 2015

28. Fioramonti P, Cigna E, Onesti MG, Fino P, Fallico N and Scuderi N: Extracorporeal shock wave therapy for the management of burn scars. Dermatol Surg 38: 778-782, 2012.

29. Saggini R, Saggini A, Spagnoli AM, Dodaj I, Cigna E, Maruccia M, Soda G, Bellomo RG and Scuderi N: Extracorporeal shock wave therapy: an emerging treatment modality for retracting scars of the hands. Ultrasound Med Biol 42: $185-195,2016$

30. Yagmur C, Akaishi S, Ogawa R and Guneren E: Mechanical receptor-related mechanisms in scar management: a review and hypothesis. Plast Reconstr Surg 126: 426-434, 2010.

31. Bravo R and Macdonald-Bravo H: Existence of two populations of cyclin/proliferating cell nuclear antigen during the cell cycle: association with DNA replication sites. J Cell Biol 105: 1549-1554, 1987.

32. Moldovan GL, Pfander B and Jentsch S: PCNA, the maestro of the replication fork. Cell 129: 665-679, 2007.

33. Nedelec B, Ghahary A, Scott PG and Tredget EE: Control of wound contraction. Basic and clinical features. Hand Clin 16: 289-302, 2000.

34. Moulin V, Larochelle S, Langlois C, Thibault I, Lopez-Vallé CA and Roy M: Normal skin wound and hypertrophic scar myofibroblasts have differential responses to apoptotic inductors. J Cell Physiol 198: 350-358, 2004.

35. Lim MJ, Ahn J, Yi JY, Kim MH, Son AR, Lee SL, Lim DS, Kim SS, Kang MA, Han Y, et al: Induction of galectin-1 by TGF- $\beta 1$ accelerates fibrosis through enhancing nuclear retention of Smad2. Exp Cell Res 326: 125-135, 2014.

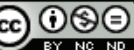

This work is licensed under a Creative Commons Attribution-NonCommercial-NoDerivatives 4.0 International (CC BY-NC-ND 4.0) License. 